\title{
LJEKOVITO BILJE I OSTALE LJEKOVITE TVARI U DJELU IVANA KRSTITELJA LALANGUA IZ 1776. GODINE
}

\author{
Autor je u radu stavio težište na opis ljekovitih biljaka koje \\ u svom radu Vračtva ladanjska spominje Ivan Krstitelj \\ Lalang (1743.-1799.).
}

\section{UVOD}

Ivan Krstitelj Lalangue (izg. Lalang), rođen 1743. godine u Belgiji u pokrajini Luxenbourg. Za vladanja Marije Terezije, točnije 1772.godine, preuzima službu liječnika u Varaždinu, gdje je 1799. godine i umro. Pored službe varaždinske vermegije vračitela i gradskog fizika, nešto kasnije, obavlja i službu župana. Medicinu je učio u Beču kod onodobno glasovitog liječnika baruna Swietena. Kao obrazovani svjetski čovjek nastojao je svoja znanja i iskustva prenijeti na okolinu, pa je u tu svrhu pisao knjižice edukativnog značaja. Među njima ističu se: Vračtva ladanjska (Varaždin, 1776.), Kratek navuk od mestrie pupkovezne ( Zagreb, 1777.), Način jabuke zemeljske saditi (Zagreb, 1788. $)^{1}$ Knjižice su pisane na latinskom (dijačkom) jeziku, a na hrvatski (starovaraždinsku kajkavštinu) su ih prevodili franjevci Eugenij Klimpacher i Edmund Platušić.

Knjižica Vračtva ladanjska, kao priručnik za neposredno terensko djelovanje u liječenju pojedinih bolesti, taksativno donosi red postupanaja, primjerice: Vužiganje gerla, (uputa na str. 126) znamenja vužiganoga gerla i koja iz njega dohajaju. Vračenje ovoga betega po receptima Nro 2, Nro 5, Nro 8 (str. 128). Recepti su u knjižici napisani pod rednim brojevima, koji se brojčano novode u terapiji pojedinih bolesti, što je jedna od znatnih prednosti i praktičnosti ove knjižice. Uz ovo, knjižica daje upute pučkim vračiteljima, barbirima, travarima i obiteljima kako će sku-

Franjo MARTINEZ, Priroda i kultura u srazu, Ogranak Matice hrvatske Čakovec, 2007. str. 64 - 68. 
pljati i čuvati ljekovito bilje za kućnu apoteku. Ona privlači pozornost i svojom jezikoslovnom stranom. Pisana starokajkavskim jezikom varaždinske varijante djelomično nas uvodi i u stanje duha naših predaka 18. stoljeća.

Djelovanje ovog liječnika-prosvjetitelja odvija se u doba kada se vlastelinski, feudalni poredak - iako na zalazu - sa svim svojim preokupacijama, u nekim dvorovima i razmetljivošću, još uvijek dobro držao. No, autor je više na strani onih u društvu kojima treba pomoći podukom i primjerom. Mahom je to običan siromašni svijet, i zato stavlja naslov, vračtva ladanjska, okrenut tom svijetu, svakako više nego li etabliranoj gospodi . Tu su prije svega "muži" - seljaci, kojima pored svih nevolja kmetskog života počesto prijeti glad i još češće boleštine. Poznate su tri gladne godine 1771. - 1773., što ga je ponukalo da napiše knjižicu (upute) NAČIN JABUKE ZEMELJSKE SADITI u kojoj detaljno obrazlaže sadnju do tada slabo poznatog krumpira. Doista uvođenje krumpira u prehranu ljudi pa i stoke smanjilo je ili čak trajno odgodilo prijeteću glad u nadolazećim razdobljima.

\section{VRAČTVENE TRAVE - LJEKOVITO BILJE}

U ovom prikazu nastojat ću usmjeriti pozornost čitatelja na botanički dio sadržaja knjižice, jer je liječenje od svog postanka vezano uz svijet biljaka. Biljke ili u ondašnjem govoru vračtvene trave, od davnina su bile u središtu ljekarničke prakse. Već je pradavni čovjek - lovac sakupljač primijetio da pojedine biljke i njihovi listovi, plodovi, kora i korijenje imaju pored hranjive vrijednosti i ozdravljujuću vrijednost. Starogrčka botanika, koju je napisao Teofrast posebno ističe ljekovita, ali i otrovna svojstva pojedinih biljaka. U prvom stoljeću Grk Pedanije Dioskorides i Rimljanin Plinije Stariji pišu zapažena djela o ljekovitom bilju koja su se kroz duga stoljeća prepisivala i nadopunjavala. Prodorom Arapa u Sredozemlje širi se arapska kultura, ljekarništvo i učinkovita primjena poznatog i nanovo unijetog ljekovitog bilja na područje Europe. Preteča ijatrokemijske terapije, čuveni Paracelsius (1493. - 1541.), pored ljekovitog bilja uvodi i anorganske tvari, jer prema njegovom shvaćanju bolest nije ništa drugo nego poremećaj vitalnih procesa u organizmu te se zato mora liječiti alkemijskim postupcima i tvarima. Za liječenje, pored biljaka primjenjuje: eterična ulja, željezo, sumpor, srebro, živu, bakar, stipsu, mineralne vode i drugo. Posebno ustraje na metafizičkom principu "quinta essetie" ili pete biti (eter) koju, prema ijatrokemičarima, imaju mnoge tvari, primjerice jestvine, mirisne tvari, sokovi pa čak i metali. Uz geslo: Sve je otrov i ništa nije otrov - ovisi o dozi!, Paracelsius uzduž i poprijeko putuje Europom, liječi ljude svojim metodama i usput glasno opovrgava do tada uhodane načine liječenja. Unatoč osporavanjima neki su se dijelovi Paracelsiusove farmakopeje održali i u Lalangovim recepturama pa čak i do danas. 
Nakon otkrića Amerike 1492. godine u Europu dospijeva mnogo do tada nepoznatog bilja čija se ljekovita i prehrambena i svojstva na veliko ispituju i neke odmah primjenjuju. Spomenuti ću samo najvažnije. To su kukuruz, grah i krumpir, najvažnije uzgojne biljke koje su uvelike spasile siromašni europski kmetski puk od kronične gladi. Može se kazati da su se pokazale kao najučinkovitija sredstva u otklanjanju te apokaliptičke prijetnje - gladi. Treba naglasiti da gotovo kroz cijeli srednji vijek kao sijelo i rasadište ", biljne apoteke" slove brojni samostani i manastiri. U svojim vrtovima samostani njeguju raznovrsno ljekovito bilje, razmjenjuju ih s drugim uzgajivačima te ispituju novounijete biljke. Misionari na povratku iz egzotičnih krajeva, primjerice Kine, Indije, Afrike, kasnije Amerike kao i brojne ekspedicije u nepoznate krajeve na povratku donose sobom različito bilje prehrambene i ljekovite vrijednosti. Samostani su čuvari literature o ljekovitom bilju. Poput ostalih knjiga tu se prepisuju i umnožavaju brojne likaruše (ljekaruše) ${ }^{2}$. Sredovjekovni samostani zapravo su bili kulturna poveznica sredovjekovlja s kulturom antike. Posebno valja istaknuti " Ordo Sancti Benedicti" - benediktince, crkveni red koji je osnovao sveti Benedikt 529. godine $\mathrm{u}$ Montecassinu u Italiji. Benediktinci su pored ostalog prevodili antičke spise poput Galena, Corpusa Hippocraticusa, te spise o ljekovima arapskih travara, maga i liječnika. Oni su u svojim vrtovima uzgajali i umnožavali ljekovito bilje i prenosili ostalim samostanima, vlastelinstvima, a i puku, sve šire u nove krajeve i zemlje. Marljivost kao vrlina koja krasi ovaj red, podudarno s krilaticom "Ora et labora" - Moli se i radi! - u ovom je poslu došla do punog izražaja.

Polovicom 12. stoljeća, u naše krajeve, spoznaje o ljekovitom bilju donose viteški redovi templari i ivanovci. Uz njihove objekte, samostane i burgove niču vrtovi kao i prostori za odmor hodočasnika, putnika namjernika, siromaka, ali i bolesnih, kojima redovnici pružaju duhovnu i tjelesnu okrjepu. Medicinska skrb podrazumijevala je primjenu lijekova po onda uhodanoj recepturi. Poglavito su to bili pripravci i čajevi iz vlastitih priručnih apoteka, spremišta i vrtova. Vremenom su su se iz takovih stacionara i skloništa razvili hospiciji - prenoćišta uz samostane i manastire, a kasnije i uz gradove. Pojedini hospiciji razvijaju se u "Hospitale" preteče današnjih bolnica s međunarodnom oznakom " $\mathrm{H}$ ". Na kajkavskom govornom području još se uvijek za bolnicu može čuti riječ "špital" ( Betežen sam i moram iti vu špital!) što potječe od riječi hospital. Zabilježeno je da hospitalci početkom 13.stoljeća osnivaju samostan i hospital u Varaždinu. Hospitale u Istri uz rijeku Mirnu i Limski kanal osnivaju templari. Vjeratno su i njima paralelni Red sv. Ivana - ivanovci imali uz svoje samostane hospicije i hospitale. Vodstvo u ljekarništvu u Hrvatskoj ostaje u rukama benediktinaca i to sve do 16 .

2 Knjiga uputa o pripremanju domaćih, starinskih lijekova na bazi bilja. 
stoljeća. Poznata su njihova sjedišta u Osoru, Splitu, Košljunu i čak na otočiću Svetcu pa i onom do danas živućem samostanu sv. Kuzme i Damjana u Ćokovcu na otoku Pašmanu. Otuda su se širila znanja i sadni materijal u druge krajeve. Postupice benediktince zamjenjuju franjevci. Do danas tiskana starija djela o ljekovitim biljkama čuvaju se u knjižnicama franjevačkih samostana, primjerice u Sinju, Visovcu, Omišu i Dubrovniku. Stari zapisi svjedoče da je u ovom dijelu Hrvatske bilo itekako dosta postignuća oko uzgoja i širenja ljekovitog bilja. U 16. i 17. stoljeću u tom se pogledu ističu velikaške obitelji Zrinski, Batthyany (Bačani), Patačići, Draškovići, Erdödy i drugi koji su uz dvorce i utvrde imali vrtove i voćnjake s uzgojnim i ljekovitim biljem sličnima vrtovima samostana. U vlastelinskim knjižnicama istaknuto su mjesto zauzimale knjige o vrtovima o uzgoju biljaka posebno onih ljekovitih svojstava. Razmjena je bila vrlo živahna. Bilje i podatci o njihovom ljekovitom djelovanju imali su status monete. Nije onda čudno da se razmjena vršila i s neprijateljskom stranom, primjerice s Turcima. Poznato je da se s hrvatske strane za otkup zarobljenih Turaka tražilo lukovičasto ukrasno bilje i sadnice ljekovitog bilja s Levanta. Razmjena se odvijala i putem poslanstava i delegacija. S istoka, prije svega Carigrada, dobili smo lijepi broj uresnih i ljekovitih flornih elemenata. Nikola VII. Zrinski, poznat je ne samo po junaštvu, učenosti, pjesništvu, već i sklonosti k uzgoju vrtlarskog i voćarskog bilja. Na širokom prostoru između čakovečke utvrde i samostana Svete Jelene Zrinski su imali vrtove i voćnjake s jestivim i ljekovitim biljem. Bili su uređeni na francuski i talijanski način sa širokim alejama čiji su se tragovi očuvali do naših dana. Zrinski je za to uređenje koristio savjete iz najboljih knjiga kojima je raspolagala njegova knjižnica. Slični vrtovi, njegovani s puno mara i ukusa bili su uz imanja i marofe u Rackanjiži (Raskrižju), Vešici, Lapčini (Lapšini), Pribislavcu, Novom Dvoru (Hlapičini). Stari opis kaštela uključuje i opis vrta i voćnjaka s kućicama vrtlara. Gospodarstvo Nova Curia (Wywdwar), danas Hlapičina, imala je i dva mlina na Muri. Ljepotom, uređenošću a posebno izborom ljekovitog bilja, o kojem su s puno pažnje vodile brigu grofice od kojih su na glasu bile Dorica Zrinski i njena snaha Eva Poppel-Lobkovitz, ističu se vrtovi Zrinskih. Uspoređivali su ih s mitskim vrtovima Alkinoosa, kao što je to učinio Jakov Tollius, jedan od važnijih europskih botaničara XVI. stoljeća. Francusko-nizozemski botaničar Carolus Clusius (1526.-1609.) boravio je na dvoru Zrinskih u Čakovcu 1579. i 1580.godine. U tom je vremenu proučavao i popisivao bilje po Međimurju i okolici Varaždina. Spomenut ću neke biljke koje je tom prilikom zabilježio. Najprije su to iglice (Anonis non spinosa, Genista tinctoria). S posebnim je interesom proučavao lukovnjače, pa slovi kao jedan od najznačajnijih botaničara za prijenos tulipana s istoka u Nizozemsku. Na livadama uz Plitvicu registrirao je narcisu (Lucoium bulbosum), šafran, bijeli i žuti zumbul. U Međimurju je zabilježio nekoliko vrsta 
orhideja i geraniuma, npr. (Genium cicutarium), hrvatski - čapljan. Istraživao je i na Greben-gradu kod Batthyanya i tu je našao nekoliko vrsta orhideja, a od lepirnjača šumski grašak (Pisum silvestre). Gljive su bile njegova trajna preokupacija, zbog čega se spominje kao "otac mikologije" - znanosti o gljivama. Zasigurno ih je proučavao i u prostranim šumama oko Greben-grada. Za neke biljke naveo je i hrvatska imena, primjerice dragoljub (Aconitum napellus), kačji jezičac (Buphthalmum vulgare).

\section{LJEKOVITO BILJE U STARIM RJEČNICIMA I LIKARUŠAMA}

Svjetski glasovita knjiga o biljkama s kasnije dopisanim hrvatskim imenima autora Castora Durantea, pod naslovom Herbario nuovo di Castore Durante (1717.), čuva se u franjevačkom samostanu na otočiću Visovcu na rijeci Krki. Matthiotijeva knjiga o ljekovitim biljkama (1568.) čuva se pri glasovitoj staroj apoteci samostana Male braće u Dubrovniku. Nekako istodobnno s ovdje razmatranim djelom Lalangua u Zaostrogu piše fra Luka Vladimirović Likarije priproste u dva jezika razdijeljene ilirički $i$ talijanski. Knjiga je tiskana u Veneciji 1775. Pavlin o. Imbro Luić napisao je 1746. ljekarušu na 55 stranica. Obasiže upute kako liječiti tegobe i bolesti primjenom ljekovitog bilja. U tom vremenu objavljuje se više knjižica ljekaruša . Pisci tih djela su poglavito redovnici i svećenici za koje možemo kazati da su bili ne samo poslenici duhovnog, nego i tjelesnog zdravlja. Fitonimija (fytón biljka, ónoma - ime) sastavni je dio starih rječnika od kojih valja spomenuti Liber de simplicibus Nicole Roccabonellija (oko 1450.), pa rječnik Lexicon Latino-Illyricum Pavla Rittera Vitezovića s početka 18. stoljeća s latinsko- hrvatskim nazivima biljka. Faust Vrančić (1595.), Bartol Kašić (1597.), Jakov Mikalja (1649.) i drugi u svojim rječnicima štokavsko- ikavske osnove bilježe fitonime (nazive biljaka) slovinski (hrvatski) i dijački (latinski). Kajkavski leksikografi kao što je najpoznatiji isusovac Juraj Habdelić (1670.) u rječniku Dikcionar ili reči slovinske z večega v kup zebrane, bilježi 150 fitonima od 10.000 svih riječi u rječniku. I kod ostalih kajkavskih leksikografa - Ivana Belostenca, Andrije Jambrešića, Franje Suška i Adama Patačića osjeća se utjecaj Vitezovićeva Lexikona. Dragutin A. Parčić (1832.-1902.), franjevac, leksikograf, u rječniku Rječnik ilirsko-talijanski-polag najnovijih izvorah, navodi 1670 fitonima. Mnoge je biljke sam skupljao kao i njihova imena od ljudi sa sela i od svojih učenika. Parčić je sastavio jedan od najstarijih naših herbarija koji se čuva kod franjevaca na Ksaveru u Zagrebu. U herbariju je prikazano 78 biljaka s naznakom imena vrsta i porodice, a za ljekovite biljke i načini primjene ${ }^{3}$

3 Nada VAJS, Hrvatska povijesna fitonimija, Institut za hrvatski jezik i jezikoslovlje, Zagreb, 2003. 
Na temelju ovih djela kao i pisane građe starijih leksikografa, a dijelom skupljene građe iz narodnog govora i velikom osobnom intuicijom, utemeljio je Bogoslav Šulek (1816.-1895.) hrvatsko znanstveno nazivlje. Tako je i nastalo Biljarstvo I. (1856.) i Biljarstvo II. (1859.), te Jugoslavenski imenik bilja, JAZU, Zagreb (1879.). Nada Vajs navodi da je Šulek izostavio oko 300 fitonima koje navodi Parčić u svom rječniku. To su uglavnom biljke tropskih krajeva koje ne rastu u nas, kao i biljke koje Parčić nije uspio determinirati.

Sintezu cjelokupnog toga golemog rada na polju imenoslovlja biljaka dobili smo u impozantnom djelu Hrvatski biljni imenoslov Ivana Šugara u izdanju Matice hrvatske, Zagreb, 2008.

Napretkom farmakognozije, grane farmacije koja se bavi proučavanjem ljekovitog bilja, sve se više primjenom kemijskih metoda ekstrakcije dolazi do spoznaja o aktivnim tvarima biljaka. Iz biljaka se izdvajaju alkaloidi, kinini, otrovi kao što je alkaloid morfin, strihnin, brucin, zatim kofein, nikotin, lobelin, kokain i ostale djelatne supstancije. Destilacijom se izdvajaju eterična ulja (terpeni), a prešanjem sluzi, ulja i masti. Umjesto nativnih biljka sve više u farmaciju ulaze razni pripravci iz biljka za što se posebno zauzimao profesor farmakognozije iz Berna Alexander Tschirch (1856.-1939.). Moderna se proizvodnja lijekova poglavito temelji na sintetskoj kemiji, sa sve izraženijom tendencijom individualiziranja lijekova. Učinkovitost lijeka nastoji se usavršiti u smislu otklanjanja njegove, po zdravlje štetne, ekspresije. Lijek koji je točno namijenjen za određenu bolest pa i za određenog bolesnika. Unatoč tomu ljekovite odlike biljaka i nadalje ostaju u središtu izučavanja, napose one koje su tek sada otkrivaju i za koje još ne znamo što skrivaju. Biljke kao lijekovi još i danas su temelj kineske ljekarničke prakse. Djelovanje tih lijekova je sporije, a učinkovita primjena traži ogromno znanje iz farmakologije.

U daljnjem prikazu knjige o kojoj je ovdje riječ usredotočit ćemo se poglavito na ljekovito bilje. Radi jasnoće i čitljivosti izostavio sam starokajkavske grafeme. Naslovnica i kazalo daju potreban uvid u onodobni popis bolesti i način njihovog preveniranja i liječenja vračtvima ladanjskim. 


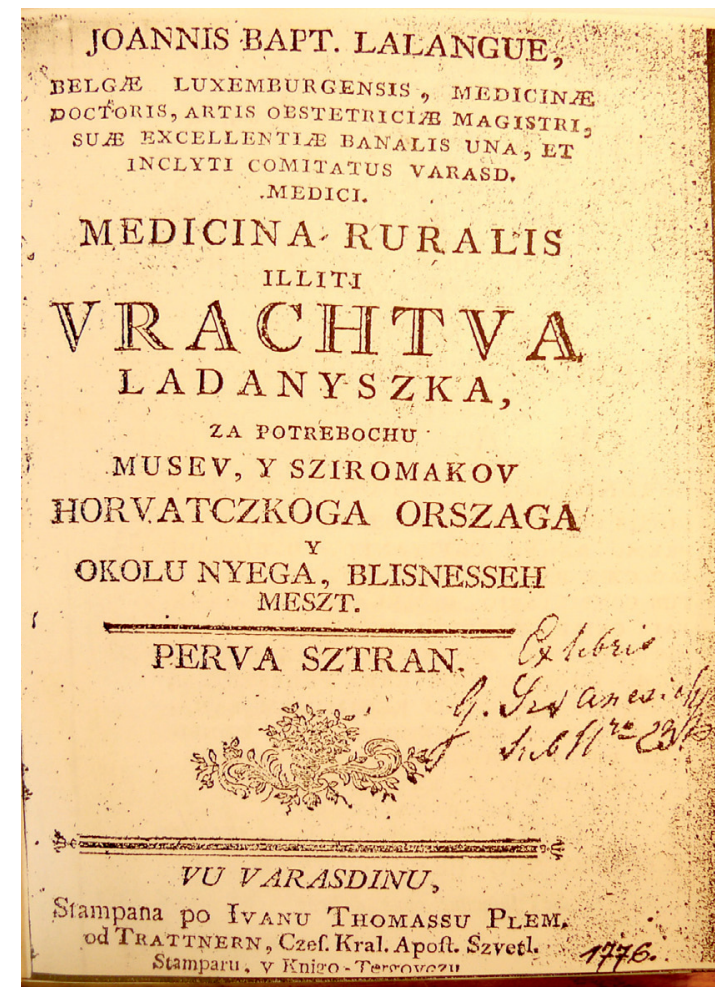

\section{VU OVE KNIŽICE ZADERŽANINEH}

DEL I. Od zrokov betegov gustešeh pri mužeh

DEL II. Od občinskoga, ali malovrednoga načina počimljučega

betega vračiti

DEL III. Od pravoga načina započimljučemi betegi baratati

DEL IV. Od zadobivajučeh zdravje

DEL V. Od vužiganja, iliti od zimlice vruče i goruče $\quad 82$

DEL VI. Od vužiganja zvunešnjega i znutrešnjega po vseh stranah tela 92

DEL VII. Od vužiganja pljuč, iliti od bodca 102

DEL VIII. Od vužiganja gerla 126

DEL IX. Od katara $\quad 131$

$\begin{array}{ll}\text { DEL X. Od gutte } & 137\end{array}$

DEL XI. Od vudarcev sunca 144

DEL XII. Od boli životne i kotrižne 147

DEL XIII. Od koz ali bobink 158 
DEL XIV. Od blekov iliti maleh kozic

DEL XV. Od verbanca, iliti zaviavice

DEL XVI Od pljuvanja kervi

DEL XVII. Od griza črevnoga, iliti zaviavice 187

$\begin{array}{ll}\text { DEL XVIII. Od gnjile zimlice } & 198\end{array}$

DEL XIX. Od zimlice malovredne i čisto zločeste 210

DEL XX. Od zimlice prepusčajuče 237

DEL XXI Od miserere

DEXXII. Od betega zlateničnoga 242

DEL XXIII. Od bele griže 246

DELXXIV. Od prave griže z boljum 251

DELXXV. Od pesje stočnosti 258

DEL XXVI. Od ispitavanj na koja potrebno bude odgovoriti kada od vračitela tolnač bude se prosil

DEL XXVII. Od načina mladice za vračtvo pobirati, nje sušiti, na prah obračati ičuvati

DEL XXVIII. Od kazitela vračtveneh trav ovde zaderženeh z kratkem preopominanjem

DEL XXIX. Od vage i od njezinoga teza koja za vaganje i merenje

vračtvih je su potrbna 318

DEL XXX. Od načina prepisavanja vračtvih i od mertuka njihovoga $\quad 320$

DEL XXXI. Od načinov napravlati vračtva

\section{DEL DVADESET I OSMI}

\section{O D}

\section{Kazitela vračtvenih trav ovde zaderžaneh s kratkem preopominajem}

Ovde ne samo vračtva vu ove knižice zaderžana i prepisana, nego takaj cenu iliti precembu vseh oneh na pervo postavlam koja se goder vu apotekah kupiti moraju, da se najmre nigdo od kupuvanja ne bude mogel plašiti, dapače za svoje zdravje tersil se bude skerbeti. Ar ona kuliko je bilo moguče jesam zebral, koja čisto malo stoje, ter vendat kruto hasnovita jesu. Zverhu toga pri vsake skoro mladice (gde je najmre za vekšu vsakoga poleščicu potrebno i hasnovito) postavil jesem vreme kada cvete, gde raste i gde se pobirati mora, ali naimre za vezdašnju potreboču ali pak za čuvanje. Kaj se vender ne mora tak razmeti kak da mladice kesneše po prepisanom vremenu pobrane čisto zevsem sega ne bi valale, nego da vu onom imenuvanom vremenu pobrane jesu najbolše kreposti i jakosti.

I zato mladica friška dobra je i hasnovita doklam goder je jošče izoštena, žmahna i dišeča. Za posušilo pak i za čuvanje mladic ili ti trav i korenja potrebno 
je kuliko je moguče vse opčinske regule gore prepisane i ove osobite ovde postavlene, verno i marlivo obderžavati. Ako vender gdo vu prepisanom vremenu za pobiranje mladic ne bi mogel dospeti more nje pobirati i potlam, doklam goder (kak malo predi jesem rekel) mladice jesu soštene i dišeče vu svoje fele, kajti kak goder dugo jedna zmed oveh kakovoč vu mladice se nahadja, tak dugo takaj mladica vu sebi svoju jakost i krepost vu vekše, ali menše hasnovitosti zderžava. Kada goder anda gdo sumlju bude imel da ova ali ona mladica menše je jakosti, kreposti i hasnovitosti, onda takve mladice vu vekšem broju naj bere i vu vračtvo naj postavla kak vsakoga malo probuvanje na zkorom hoče navčiti i uputiti. I ako gdo kakvu dvojmbu bude imel, vender ja vu Varasdinu stanujem i naj se meni na ušano oglasi i vsakomu ove knižice čtavcu vsigdar na službu buden pripraven.

Vezda sledi kazitelj vračtvenih trav i korenja poleg reda perveh njihoveh litter horvatskem (kuliko naimre bilo je moguče iztolnačiti), diačkem ( kratica d.) i nemšskem (kratica n.) jezikom za polešicu čtavca na pervo ovde posztavlen.

A.

Aniz trava, drugač Slatki komin, diach. Anisum, nems. Anaiskraut. Raste po verteh, seme je hasnovito.

Arnika trava, diach. Arnica, nems. Worseleikraut. Raste po ledinah i po mokrešeh mestah, po visokej takaj gorah i planina. Cvete meseca jakovsčaka i velikomešnika. Cvetje je hasnovito.

B.

Berečna trava, drugač Leken, d. Nymphea, n. See - Blumenkraut. Raste po berekeh i po potokeh koi polehko tečeju i kakti na polovicu stoje. Listje njeno je široko i zverhu vode raspersteto. Meseca velikog travna i ivansčaka cvete, negda pak v jeseni belo, ali k blatu spodobno ima cvetje. Koren, listje i cvetje jesu hasnovita. Listje posušeno nikaj ne vala.

Bersa vinska zgotovlena za prekhitanje d. Tartarus eneticus, n. Brech-Weinstein. Unca iliti dva lota stoje četiri ranjske. Anda dve zerne kupiti se moreju za jeden krajcar.

Betonika trava, drugač serpec d.Betonica, n. Betonienkraut. Raste po šumah i po germju. Cvete meseca jakopvščaka i velikomešnika. Pobirati se mora ivanščaka.

Bezgovo drevo d. Smbucus, n. Holderbaum. Ovo drevo vsem je znano, po plotah i poleg sel najrajši raste. Listje, cvetje, kora i zernje njegovo je hasnovito.

Bobovnjak vertni d. Nasturcium hortense, n. Gartengrez. Seje se po verteh i dva puta na protuletje v letu i jeseni. Trava je hasnovita, ali se ne čuva.

Bobovnjaka zdenčni, drugač punkres, d. Nasturcium aquaticum, n. Brunengresz. Po potokeh zdenceh rad raste. Cvete meseca jakopvčaka i velikomešnika, ali onda je menše kreposti. Friška njegova trava je hasnovita, posušena nikaj ne vala. 
Bobunjak vodena trava, d. Veronica beccabunga, n. Bachbungenkraut. Raste pojeg krajov potikov i po berekeh. Pobirati se mora na protuletje i za hasen zeti, ne čuva se na dale, v letu cvete i suha nikaj ne vala.

Boraga trava, drugač volovski jezik, d. Borrago, n. Boragenkraut. Raste po verteh sama od sebe i po polju ne oranom meseca velikokoga travna i ivanščaka cvete. Listje i cvetje je hasnovito.

Borovica drevo, d. Juniperus, n.Kranabethbeern. Raste po gorah i šumah. Koren, sveršje, listje i zrnje je hasnovito. Zrnje pobirati se mora kada zazrele i črno postane.

\section{C.}

Čerlenec luk, d. cepa, n. Zwiebel. Raste po polju. Koren i listje je hasnovito; ter veliko stanovito božansko dobročinjenije vu ovom našem orsagu kaiti ne samo muže i priproste ljudi hrani, nego i od vnogeh betegov zderžava.

Červinjak trava, drugač gerliček, d. Tanacetum, n. Wrmkraut. Raste poleg putov na polju i poleg krajov grab meseca jakovčaka i velikomešnika cvete. Sama trava i cvetje je hasnovito. Pobirati se more ivanščaka i jakopvčkama meseca.

Češmigovina, d. Berberis, n. Sauerdorn. Po našeh stranah vu množine raste poleg plotov, poleg putov i po germju. Sad njeni malomešnika meseca dozrele. Listje i sad je hasnovit. Listje ne za čuvanje.

Češnjak luk, d. Allium, n. Knoblauch. Raste po vertah i seje se po polju. Koren je hasnovit i čudnovite proti betegom jakosti, navlastito pri mužeh koi više krat ob njem živeju.

Češnjak vodeni, d. Scordium, n. Waserknblauch.Raste po mestah mokreh i berečneh, poleg grab vodeneh meseca ivanščaka i jakopvčaka cvete. Trava iliti listje njegovo je hasnovito.

Centauria trava ili jezero zlatna trava d. Centaurium minus, n. Tausendguldenkraut. Raste po polju i po šumah mokreh. Listje i cvetje je hasnovito.

Cikoria trava, d. Cichorium, n. Cichorikraut. Raste po vertah navlastito pak poleg putov i po mesta zapušeneh. Koren i listje je hasnovito, suho nikaj ne vala. Ako bi se pak gdo mešel i puntal vu razlučvanju i poburanju cikorije, tarakse i kozlove brade trav, to nikaj ne škodi koju goder bude bral kaiti su jednake kreposti i hasnovitosti.

D.

Detelja ledinska, d. Trifolium pratense purpureum, n. Kleekraut. Raste po ledinah po spašnikah i po moreh mestsh. Seje se po polju za konje meseca maloga i velikoga travna i ivanščaka cvete. Listje prez ali z cvetjem je hasnovito.

Detelja zimličavka, d. Trifolium fibrinium, n. Fieberkleekraut. Raste vu vodah berečneh stoječeh i po drugeh mokreh mesta. Meseca velikoga travna i ivanščaka cvete. Koren i listje je hasnovito. 
Divji šafran v jeseni cvetuč, d. Colchicum autumnale, n. Herbstblumenkraut. Raste nai više po ledinah mokreh. Dvojversni koren ima, jeden je suhi drugi je frišek i szošten. Suhi nikaj ne vala, friški je hasnovit, pobirati se mora v jeseni. Kada hoče cvesti more se brati i na protuletje, ali bolši je v jeseni.

Dobra misel trava, d. Origanum vulgare, n. Wollgemüthskraut. Raste po mestah poliszkeh gorskeh, suheh sunčeneh, po germju i poleg putov, jakopvčaka i velikomešnika cvete. Trava prez ali z cvetjem je hasnovita.

Drenovo dervo, d. Cornus, n. Welscherkirschenbaum, ali Kornelbaum. Raste po vertah i po živicah iliti po germju. Sad je hasnovit, maloga travna cvete vu jakopvčaku sad dozrele.

Duhan, d. Nicotiana tabacum, n. Tabak. Seje se vu ovom orsagu, listje je hasnovito.

G.

Galic beli, d. Vitriolum album, n. Weisen calicestein. Je hasnovit. Funt stoi jeden raniski i četiri krajcare, pol kvintice vala jeden pfenik.

Gamilica trava, d. Camomila, n. Cammilenkraut. Raste obilno po polju i po ledinah. Cvetje z travum dišečum je hasnovito.

Graciola trava, d. Gratiola, n. Wildaurinkraut. Raste poleg potočankov i po ledinah mokreh. Ocvete ivanščaka, jakopvčaka i velikomešnika meseca. Koren i trava je hasnovita.

Grozdičje drobno ivanjsko, d. Ribes, n. Joans Beerstaud ali Rieber. Raste po verteh. Sad iliti zernje je hasnovito.

Gruda zemlje od Armenie, d. Bolus Armena, n. Armenischer bolus. Jeden funt od nje vu svojem sobstvu stoi trideset i dva krajcera. Vu prahu pak vala četrdeset i osem krajcerov. Vsaki lehko more nju na prah obernuti.

Gummi smola harapska, d. Gummi arabicum, n.Dünten gummi. Funt stoi trideset i dva krajcara.

H.

Hebed trava, d. Ebulus, n. Attichkraut ali Niederholder. Poleg občinskeh i orsaškeh putov i poleg krajov polskeh rad raste. Koren, steblo, kora, listje i zernje je hasnovito.

Herg tikva za pusudje, d. Citrullus, n. Angurienkraut. Seje se po verteh. Seme iliti koščice jesu hasnovite.

Hrastovo drevo, d. Quercus, n. Eichelbaum. Cele šume iz hrastja jesu navadne biti. Kora i listje je hasnovito. Cvete maloga i velikoga travna.

Hren občinski, d. Armoracea, n. Krein ali Scharfe Retich. Koren je hasnovit, na stolu jè se $\mathrm{z}$ govedinum.

Hruškovo drevo, d. Pirus, n. Birnbaum. Sakojačke fele sada ima i saki je hasnovit, navlastito koi je sošten. 
J.

Jabukovo drevo, d. Malus, n. Apfelbaum. Ovoga dreva vsakojačke jesu fele razlučeni sad donašajuče vsaki je hasnovit, zrel i na pol zrel.

Jačmen, d. Hordeum, n. Gerfte. Seme je hasnovito.

Jalapa koren, d. Jalapa, n. Jalapa wurzl. Ov koren je hasnovit. Vu svojem sobstvu stoi funt tri raniske i dvanaist krajcerov. Vu prahu pak kupiti se more za četiri raniske i šesnaist krajcerov. Vsaki njega bude znal na prah obernuti.

Jalša drevo, d. Alnus, n. Erlenbaum. Raste po mokreh i berečneh mesta poleg potokov. Kora i friško listje je hasnovito, ali listje ne čuva se.

Jalun, d. Alumen, n. Alaun. Fertali funta stoi tri kraicere.

Januš slatki, d. Feniculum, n. Fenichelkraut. Listje i seme je hasnovito, ne čuva se listje.

Jesenovo drevo, d. Fraxinus, n. Eschenbaum. Raste po šumah. Kora je hasnovita.

Jezičec trava, drugač Kunica, d. Millefolium, n. Schafgarben. Skoro vsigde raste poleg putov, po mestah suheh, zapuščeneh i po ledinah. Celo leto najbole pak meseca ivansčaka cvete. Trava i cvetje je hasnovito i zato se obodvoje more se skupa pobirati.

Ižop vertni, d. Satureja, n. Satureikraut. Raste po verteh. Trava je hasnovita, pobirati se mora velikomešnika.

K.

Kafra, d. Camphora, n. Campher. Pol funta stoi tri raniske, četrdeset i četiri kraicere.

Kelj zelje, d. Brašica, n. Köllkraut. Raste po verteh je hasnovit.

Kina, d. China, n. Fieber-Rinde, ali Jesuitischer Baum. Jeden funt vu svojem sobstvu stoi četiri raniske i šesstnaist kraicarov. Vu prahu pet raniskov. Vsaki znal bude na prah obernuti.

Kiselica, d. Acetosa, n. Sauerampser, po ledinah vu vnožine raste nahadja se i po verteh. Cvete velikoga travna. Koren i trava je hasnovita. Trava samo friška je dobra. Kiselica mala dosta spodobna k detelje jednake je kreposti i raste po šumah okolo korenja drevja, kakti takai po jarugah.

Kolmus koren, d. Calamus aromaticus, n. Calmus. Raste po mesteh mokreh i berečneh, poleg potokov takaj vu Varaždinu v grabe okolu grada vnogo se njega nahaja, drugač vu štacununeh prodaje se.

Komin, d. Caroum, n. Kümmel. Raste po verteh i po gorah se negda nahadja. Seme je hasnovito.

Konoplja, d. Canabis n. Hans . Seje se od dobreh gospodarov. Seme je hasnovito i olje od onud napravleno. 
Konsčica repa, d. Napus, n. Steckruben. Seje se po polju i teško se razlučava od domače repe, kajti je krepost i žmah jednak.

Kopitnjak trava, drugač mesečnak, d. Hedera terrestris, n. Gundelrebenkraut. Raste po verteh poleg plotov, cvete maloga travna je hasnovita. Mora se pobirati velikoga travna i inaščaka, dapače celo leto.

Kopriva trava, d. Urtica, n. Brenneffel. Raste skoro vsigde, po verteh po mesta zapoščeneh, poleg plotov i po grabah blizu zidov. Cvete ivanščaka jakopvčaka meseca. Trava je hasnovita, pobirati se mora kada počne cvesti velikoga travna i ivansčaka.

Koren okolo leskovoga dreva navaden rasti, d. Asarum, n. Hafelwurzelkraut. Raste po šumah i germju navlastito pak poleg leskovoga korenja. Cvete maloga i velikoga travna i ivansčaka meseca. Koren i listje jesu hasnoviti.

Koren veliki, d. Enula, n. Alantkraut, je jako hasnovit. Raste po mestah mokreh na Viničke fare njega je vnožina. Cvete jakopvsčaka i velikomešnjaka.

Kozlova brada trava, d. Tragopogon, n. Bocksbartkraut. Raste po ledinah i spašnikeh mokreh, dapače skoro vsigde. Cvete velikoga travna, ivansčaka pak cvet opada, potlam seme po jakosti cveta vu zrak odleti doklam z vremenom nazad na zemlju opadne. Drugoč cvete jakopovčaka i velikomešnika. Koren i trava je hasnovita. Ova trava vnogo je spodobna k cikorie i k tarakse travam ali nikaj ne bude škodilo ako gdo jednu , drugu i tretju skup bude mešal i bral, kaiti su jednake kreposti.

Kersulica trava, d. Choerefolium, n. Körbelkraut. Rada raste po verteh i vu Varaždinu poleg plotov. Trava je hasnovita.

Kraljevsko serdce trava, drugač Margetica, d. Verbascum, n. Himelsbrandkraut. Raste po mestah pesčeneh, po polju, poleg putov, po sipeh, negda i negda po zaposčeneh zidinah i stareh stenah. Cvete meseca ivansčaka, jakopovsčaka, veliko i malo mešnjaka. Cvet i listje je hasnovito. Listje za čuvanje mora se pobirati ivansčaka meseca.

Kukuruza, d. Fagopirum, n. Heidenkorn, sadi se po polju. Seme iliti zernje je hasnovito iz njega biva melja.

Kupina čerlena, ali bela, d. Rubus ideus, sive ruber, vel albus, n. Hinbromenftaudt. Raste po sivicah mokreh i vu hladu postavlenih, takaj poleg jarug kud se voda scedja i po verteh. Cvete velikoga travna i ivasčaka. Sad njein jakopovčaka dozrele koi z listjem je hasnovit.

Kupina černa, d. Rubus niger, n. Brombeerftaudt. Vsigde raste poleg plotov po germju, poleg putov i krajov poljskeh, po živicah i poleg goric. Cvete v letu, v jeseni dozrele. Listje verhunci zeleni i sad jesu hasnoviti.

Kutinja drevo, d. Cotonea malus, n. Qilittenbaum. Raste po verteh i po vinogradeh. Sad je hasnovit. 
L.

Lanje golubovo, d. Stercus columbarum, n. Taubendreck, je hasnovito.

Lanje konjsko d. Stercus equinum n. Rofzdreck, je hasnovito.

Ledinsko cvetiče, d. Bellis n. Maslliebenkraut. Raste na vnožine po ledinah i po spašneh mestah. Cvete na protuletje. Lističe i cvetje je hasnovito.

Lipovo drevo, d. Tilia, n. Lindenbaum. Cvete velikoga travna, ivansčaka i negda jakopovsčaka. Cvetje i zernje je hasnovito.

Lopuh veliki, d. Bardana, n. Glattenkraut. Raste vu mestah zapusčeneh, poleg putov i sel. Koren, listje i seme z bodečemi skupa kapicami i oklopmi jesu hasnovita. Cvete jakopovčaka i velikomešnika. Ne čuva se listje nego doklam je friško mora se pobirati i potrebuvati.

Loj, ali masča, d. Scevum,seu pinguedo porcorum boum \&e, n. Schmalz, hasnovita je.

M.

Mačkina trava, d. Nepeta, n. Katzenkraut. Raste po polju, diši kakti metica. Ivansčaka i jakopovčaka cvete.

Majuran, d. Majorana, n. Majorankraut. Po verteh raste, trava je hasnovita.

Mak beli $i$ černi, d. Papaver album E nigrum, n. Weise und schwarze Mohnkraut. Po vertu raste, ako se v jeseni poseje na protuletje vun izide, $\mathrm{v}$ letu cvete $\mathrm{k}$ jeseni dozrele. Seme je hasnovito.

Mak čerleni poljski, d. Papaver rubrum, sive erraticum, N. Rothe Kornblumenkraut. Cvetje je hasnovito vsigde se nahadja i raste navlastito med sitkom na polju. Cvete velikoga travna, ivansčaka i jakopovsčaka.

Mandalovo drevo, d. Amygdalus, n. Mandelbaum. Raste po verteh i po vinogradeh. Seme vu koščicah zaderžano je hasnovito.

Materina ali babina dušica, d. Serpillum, n. Cuendelkraut. Raste po brežnjateh mestah, po polju i po suhej spašnikeh nairaši. Ivansčaka, jakopovčaka i velikoga mešnika cvete. Trava je hasnovita.

Med, d. Mell, n. Hönig, je hasnovit.

Mehenj po drevu, d. Museus vulgaris, n. Moos. Vu šumah i korah po drevju i po pečinah raste, je hasnovit.

Melj trava, d. Lupulus, n. Hopfenkraut. Raste po ploteh u po verteh, za pivu vala. Cvete meseca jakopovčaka i velikomešnika. Trava je hasnovita.

Metica, d. Menta, n. Münzenkraut. Raste po vertah i po ledinah blizu berekov. Trava je hasnovita, cvete jakopovčaka.

Metica gorska, d. Calaminta montana, n. Bergmünzenkraut. Raste po bregeh i po šumah, po mestah pesčenih i sunčeneh. Trava je s cvetjem hasnovita, pobirati se mora velikomešnika. 
Metica konjska, d. Pulegium, n. Polejkraut. Raste na verteh i po mestah mokreh, zaposčeneh poleg potokov i berekov. Jakopovčaka i velikomešnika cvete. Trava je hasnovita.

Mirha iliti plemenita mast, d. Mirrha, n. Mirrhengummi. Pol funta stoi trideset i dva kraicera.

Mleko, d. Lac, n. Milih. Je hasnovito kakti takai stepki i sirotka.

Mleko vučje trava, d. Esula, n. Wolfsmilchkraut. Raste vsigde poleg putov i po šumah. Cvete velikoga travna, ivansčaka, jakopovsčaka i velikomešnika. Koren i trava je hasnovita.

Murva dudovina, d. Morus, n. Maulbeerbaum. Sadi se po verteh, sad je hasnovit koi je bel ali čern.

Muštarda, d. Sinapi, n. Senfkraut. Seje se po verteh i po polju. Seme je hasnovito.

Muštarda divja, d. Erisintum, n. Weegfenskraut. Raste zverhu zidin zapuščeneh i po polju. Cvete velikoga travna. Trava je hasnovita ali ne za čuvanje.

N.

Netresk trava, drugač Volovsko oko, d. Sedum žive Semper vivum, n.Hauswurzenkraut. Raste po stareh zidinah i po poderteh hižah. Po ivanju cvete, potlam se posuši. Kada vjeseni seme dozrele i zato ne čuva se za zimu. Sama trava je hasnovita.

Natragulja, drugač Teleča noga trava, d. Arum, n. Pfasenschwantz. Raste po šumah i po mestah vu hladu postavleneh poleg putov i plotov. Koren je hasnovit listje malo gda.

O.

Olikovo drevo, d. Olea, n. Olivenbaum. Sad je hasnovit odkud se napravla olje koje vezda je dražešu cenu vezda je ležešu, kak je vsakomu znano.

P.

Pasternjak, Bela merkva, d. Pastinaca, n. Pasternak, ali Weiseruben. Raste po verteh i po ledinah. Koren i listje je hasnonovito.

Pelin, d. Absinthium, n. Wermuthkraut. Raste po verteh poleg putov i sel. Sam se od sebe zaderžava, jakopovsčaka cvete. Listje i verhunčeci njegovi jesu hasnoviti.

Peršun vertni, d. Petroselium, n. Peterfilkraut. Raste po verteh i mokreh mestah vu vnožine kada se poseje. Trava i koren je hasnovit.

Plaibas farba, d. Cerusa, n. Ordinari bleiweis. Funt stoi trideset i dva krajcara.

Pljučnjak, d. Marubium, n. Weiser Andorn. Raste po orsačkeh i občinskeh puteh poleg krajov polja vu mestah zapusčeneh i zaostavleneh. Trava je hasnovita, vletu cvete, pobira se ivansčaka. 
Pljučnjak piknjavi, d. Pulmanaria, n. Lungenkraut. Nekoi je drevast, nekoi pak piknjav i kakti zamazan. Raste po šumah, po bregeh i po gorah vu hladu postavleneh. Cvete sušeca meseca, maloga i velikoga travna, pobirati se mora maloga travna. Trava je hasnovita.

Pljučnjak po hrastovom drevu, d. Lichen arboreus, n. Eichel Lungenkraut. Raste po starom hrastovju, bukovju, cmrekovju i po ostaleh strankah drevja i to po gusteh i vu hladu postavleneh šumah. On je naibolši koi raste po hrastju. Vu pomenkanju ovoga valal bude i od drugeh drev, ali vendar hrastja vsigde je za dosta.

Podbel trava, d.Tussilago, n. Rofshus ali Huflattich. Raste po mokreh mestah poleg potokov, zdencov i grab, po zemljah takaj dobro gnojneh na koncu meseca sušca i na pričetek maloga travna cvete.

Poklonec pričerni, d. Pulsatilla, n. Schwarzliche Vindblumenkraut. Raste po mestah sunčeneh. Cvete maloga travna. Trava je hasnovita. Nahadja se takai poklonec priprosti i kakti občinski, ali vnogo se razlučava od pričernoga kaiti vu vusta postavlen ne tak žarguč kak je pervi koi vusta žari i za jezik gize, zadnji anda nikai ne hasni.

Porluk, d. Porrum, n. Lauchkraut. Raste po verteh. Koren i trava iliti listje kruto jako je hasnovito kakti črlenec i češnjak.

Povertnica, d. Raphanus, n. Rettih. Raste po verteh i po polju. Koren je hasnovit.

Predivo, d. Linum, n. Flachs. Seje se na polju. Seme je hasnovito i olje od njega napravleno.

Preprut trava, d. Filis, n. Farrenkraut. Raste poleg putov i po šumah, navlastito mokreh. Cvete jakopovsčaka. Koren i trava je hasnovita.

Preprut vodena, d. Capilli veneris, n. Frauenhaar. Raste poleg krajov zdencev i poleg grab od vode prehadjajuče poškropleneh. Raste takaj poleg potokov med mokrem kamenjem. Celo leto zmirom je zelena i kada se nahadja poleg zdencov vnogi veliu i štimaju da je zato onde dobra voda. Trava njeina je hasnovita.

Protuletno pervo cvetičje, d. Pimula veris, n. Peterfchliselkraut. Raste po polju, po ledinah mokreh, po živicah i šumah. Na protuletje cvete. Cvet je hasnovit.

Pšenica, d. Triticum, n. Weizen. Seme je hasnovito iz kojega melja biva.

R.

Repa, d. Rapa, n. Ruben. Raste po verteh i po polju. Trava i koren je hasnovit

Roža, d. Rosa, n. Rosenstaudt. Felja je vsakojačka. Raste po verteh, cvete velikoga travna. Cvetje je hasnovito.

Rožmarin, d. Rosmarinus, n. Rosmarin. Raste po verteh. Cvetje i listje je hasnovito. 
Rutica trava, d. Rutha, n. Rauttenkraut. Raste po verteh suheh i naproti suncu postavleneh. Ivančaka cvete onda naj se pobira.

\section{S.}

Sabjak trava, d. Ranunculus pratense, n. Fröschpfefer. Raste po ledinah suheh i visokeh, po spašnikeh, po mestah pesčeneh i kameniteh. Koren i listje je hasnovito. Velikoga travna cvete. Nahadja se takai druga felja ove trave koja se zove Sabjek berečni; raste po berekeh i po mokreh mestah. Cvete velikoga travna i ivansčaka. Sama trava je hasnovita.

Salfia, d. Salvia, n. Salbeikraut. Raste po verteh. Listje prez, ali z cvetjem je hasnovito. Po polju suhešem po sivicah i ledinah takaj raste i zove se Salfia šumska. Cvete obodvoja felia ivansčaka i jakopovsčaka.

Sčav veliki trava, d. Lappatum, n. Gründkraut. Raste po polju i po mestah zapusčeneh. Trava i koren je hasnovit.

Sčir trava, d. Marcurialis, n. Bingelkraut.Raste po cintoreh, po verteh, po vinogradeh i po mestah mokreh, $\mathrm{v}$ hladu postavleneh. Trava je hasnovita, cvete $\mathrm{v}$ letu i v jeseni.

Scalina človečanska, d. Urina humana, n. Menschenharn. Je hasnovita, ali mora biti od zdravoga i srednje dobe človeka, kuliko je moguče.

Železo, d. Ferrum, n. Eisen. Je hasnovito, ali se mora predi piliti metem toga ne mora biti hergiavo. Poglei funt seleza spilenoga stoi šesnaest kraicerov. Vsaki bude sam znal spiliti kak je vu imenuvanom broju prepisano.

Salata, d. Lactuca, n. Lattich ali Salat. Seje se na verteh. Trava je hasnovita.

Salata velika rugana, d. Endivia, $\mathrm{n}$. Endivienkraut. Trava je hasnovita.

Španjolska muha, d. Cantarides, n. Spanische Mucken. Akoprem ovakove muhe navadne je su stanuvati i naradjati se samo po topleh kraljestva, vender i vu našeh kada je vručina i vu ostaleh Europe strankah v letu se nahadjaju po verteh, zvarhu drevja i sversja njihovoga, metem toga ne vu tulike vnožine kak vu topleh orsageh, gde zarad vsedilne vručine zmirom se poradjaju. Ovakove cele muhe jesu hasnovite. Vu svojem sobstvu pol funta iz njih stoi jeden raniški, trideseti šest kraicarov. Vu prahu pak tri raniške i dvanaist kraicarov. Od kuda bole je nje kupiti svojem sobstvu i vsaki poleg mojega navuka nje na prah bude mogel obernuti.

Sporiš trava, d. Verbena, n. Eisenkraut. Raste poleg putov, po polju, poleg plotov i poleg sten, vu mestah zapusčeneh. Cvete ivansčaka, jakopovsčaka i velikomešnika. Trava je hasnovita prez ali s cvetjem.

Žveplo, d. Sulphur, n. Schwefel. Cvetje od svepla farbe citronske je hasnovito. Funt stoi trideset i dva kraicara. 
Suta merkva, d. Daucus, n. Gelbe Ruben. Seje se po verteh i na polju. Koren i seme je hasnovito. Je takaj druga felja ove merkve, koja po gorah poleg putov navada je rasti samo njeino seme je hasnovito.

Saliter gotovi, d. Nitrun depuratum, n. Preparirte Salniter. Funt stoi dva raniska i osem kraicarov.

Sena trava pres stebla, d. Senna fine stipitibus, n. Stenesblätter ohne ftengeln. Listje je hasnovito. Funt stoi dva raniska i osem kraicarov. Pol unce iliti jeden lot vala četiri kraicare, vu prahu pak funt stoi tri raniske i dvanaist kraicarov, anda osmi dei unce iliti jedna kvintica stoi jeden kraicar i pol. Vsaki more ovu travu na prah obernuti .

Sirek, d. Panicum, n. Fuchsschwantz ali Welscher hirs. Seje se i vu našem orsagu.

Slez beli, d. Althea, n. Eibisch. Raste po verteh i nahadja se po polju vsigde okolu brežankov. Cvete v letu, hasnovito je listje, cvetje i koren.

Slez černi, d. Malva, n. Papelkraut. Raste poleg plotov i stez po mestah zapusčeneh, po veteh takai. Trava i cvetje je hasnovito.

Slivovo drevo, d. Prunus, n. Zweschgenbaum. Raste po verteh i vsakojačke fele se nahadja koja rastučen sad doprinaša, vsaki je hasnovit. Ako je pak ovakvo drevo zapusčeno zove se šumsko i raste po mestah zaostaleneh.

Sok, iliti sošt makovoga semena, d. Opium electum, n. Truckener Megenfast. Je hasnovit. Unca iliti dva lota stoje trideset i dva kraicara.

Sol občinska, d. Sal commune seu Culinare qualecunque, n. Saltz je hasnovita.

Sol žuhka, d. Sal amarum, n. Bittersalz. Funt stoi negda deset negda dvanaist groši, hasnovita je.

Sopun občinski, d. Sapo ordinarius, n. Gemeine seisse je hasnovit.

Sopunica trava, d. Saponaria, n. Seisenkraut. Raste blizu potokov i stječeh vod, nahadja se takaj po germju i po ledinah mokreh i mesta pesčeneh. Cvete velikoga travna, ivansčaka i jakopovsčaka. Trava prez ali z cvetjem je hasnovita.

Srablivka trava, d. Scabiosa, n. Scabiosenkraut. Raste med sitkem po polju, po ledinah i mekotah. Cvete ivansčaka i velikomešnika. Trava je hasnovita. Druga tak je felja ove trave koja raste po mestah zapusčeneh, po ladinah i spašnikeh, po germju pesčenom i mokrom. Cvete na pričetek jeseni, jednako je hasnovita kakti perva, zato skupa moreju se pobirati i čuvati.

Svinski bob, d. Hyosciamus, n. Bilsenkraut. Raste poleg putov i grab. Listje prez ali z cvetjem i seme je hasnovito, v letu cvete.

T.

Taraksa trava, d. Taraxacum, n. Pfasenblatt, ali Pfasenröhrlkraut, spodobna je $\mathrm{k}$ cikorie i kozlove brade trave, zato moreju se $\mathrm{z}$ kupa pobirati kaiti su jednake 
kreposti. Ova trava raste po verteh i po spašnikeh, takaj okolu polskeh krajov. Cvete na protuletje i v letu počimljuč od maloga travna. Trava i koren je hasnovit, trava se ne čuva.

Temniam, d. Olibanum in forte, n. Ordinari Weichrauch. Pol funte stoi trideset i dva kraicara.

Tern beli, d. Rhamnus, n. Wegendorn. Raste poleg plotov po grabah i po mokrom germju. Černo zernie, iliti sad je hasnovit. Cvete meseca velikoga travna okolu sesvetčaka zernje i sad zrelo biva i onda taki more se pobirati.

Ternina drevo, d. Acacia, n. Schlehendorn, ali Kekschlehen. Raste po germju i poleg plotov. Koren, listje i sad je hasnovit. Sad pobitarati se mora v jeseni kakti takaj sušiti i čuvati.

Terputec trava, d. Plantago, n. Wegrchkraut. Raste po velikeh puteh, po dvorisčami, po ledinah i po ostaleh zelenih i travnateh mestah. Cvete velikoga travna i ivansčaka. Koren i trava je hasnovita.

Ters, d. Vitis, n. Weinreb. Njegovi verhunci ( z kojim se rozgve kolja poprijemljeju) kakti takaj grozdje zrelo i nezrelo, vino, žganica i ocet jesu hasnovita.

Tikvanja, d. Cucurbita, n. Kurbis. Sadi se po verteh i po polju dobra je za jesti. Seme njeino je hasnovito.

Timian trava, d. Thymus, n. Thimiankraut. Seje se po vertah, trava je hasnovita.

Trava dim zemeljski, d. Fumaria, n. Erdrauchkraut. Raste po polju i po mestah za povertelje pripravleneh. Trava z cvetom je hasnovita. Ivansčaka i jakopovsčaka cvete i onda naj se pobira.

Trava kufna zvana, d. Petasites, n. Pestilenzkraut. Raste po mestah mokreh poleg potokov, berekov i stoječeh vod. Koren i listje je hasnovito.

Trava oštrica, d. Gramen, n. Graskraut. Raste najviše po polju. Trava i koren je hasnovit. Trava posušena nikaj ne vala.

Trava svetog Ivana, d. Hypericum, n. Joanneskraut. Raste po polju i po šumah, ivansčaka cvete. Cvetje z listjem je hasnovito.

Trava svetog Petra, d. Parletaria, n. Maurerkraut. Raste po stareh i zapusčeneh stenah. Trava je hasnovita, v letu cvete.

Trepetin občinski, d. Terebintina communis, n. Gemeine Terpentin, funt stoi kaicarov šestnaist.

Trubelika trava d. Cicuta, n. Schirling. Raste rada okolu plotov i po germju, vnoge je felje ali ona sama je dobra koja je pričerna, i med perstimi zdruzgana na spodobu mišje duhe smerdi. Cvete ivansčaka meseca. Trava je hasnovita

Tusčak trava, d. Portulaca, n. Porzelkraut. Raste po verteh , po dvorisčah, po mesta zapusčeneh i po mestah pesčeneh, blizu velikeh vod. Trava je hasnovita, posušena nikaj ne vala. 
V.

Vapno živo, d. Calx viva, n. Kalch, je hasnovito.

Verbnica trava, d. Salicaria, sive Lysimachia, n. Weiderichkraut. Gde se verbje nahadja onde med njim rada raste. Ivansčaka i jakopovsčaka cvete, je hasnovita.

Verbovo drevo, d. Salix, Weiden ali Felbenbaum. Rate po mestah mokreh poleg vod i berekov, poledinah takaj od dobreh gospodarov presadjuje se na mesto plotov. Listje i guba po ovem drevu rastuča je hasnovita.

Veronika trava, d. Veronica, n. Ehrenpreiskraut. Raste po mestah priprosteh, zapusčeneh i kameniteh, po spašnikeh, poleg plotov, po germju i brežankeh sunčeneh. Na protuletje i v letu cvete. Zeleni se celo leto, velikoga travna i ivansčaka naj se pobira. Trava je hasnovita.

Vuzgorek, d. Cucumis, n. Gürchen ali Cucumer. Seje se po verteh i po polju. Sirov i kuhan dober je jesti. Seme je hasnovito.

\section{Z.}

Zelenoča kufra, d. Viride aris, n. Grünnfpan, pol funta stoi četrdeset i dva kraicara.

Zemeljska tikva, d. Bryonia, n. Zaunruben. Raste na vnožinu poleg plotov navlastito vertneh. Cvete velikoga travna i ivansčaka. Koren je hasnovit.

Zob, d. Avena, n. Haber. Seme je hasnovito.

Za pravilno doziranje ovih vračtvenih tvari u knjižici se navode mjere kojima se određuje masa tih tvari, što je posebno važno kod vračtva koja pored ljekovitih imaju i neka otrovna djelovanja.

\section{Vage i od njeinoga teza koja za vaganje i merenje vračtvih jesu potrebna}

Tez vage počimlje se po jednom zernu. Od jednoga zerna ide se na jeden skrupel, od jednoga skrupela na jednu kvinticu, od kvintice na unciu iliti na dva lota, od uncie na funt. Zerno pak je smekčina jednoga postavemo jačmenoga zerna srednje velikoče. Skrupel je smekčina dvadeset i četiri zern. Kvintica vu sebi zaderžava tri skrupele iliti sedamdeset i dve zerne. Uncia derži osem kvintic iliti petstosedamdeset i šest zern. Funt zadnič šestnaist uncih.

Na vagu takaj dugovanja čversta za vračtvo potrebna postavljaju se po sakah po sačicah po paru i po broju. Dugovania pak soštena i cureča važeju se na pint, na pol pinta, na frtalj, na pol fertalja, na unciu i na kaplju. Saka zove se ono kaj goder človek zevsum rukum i z perstimi more prijeti.

Za pojašnjenje ovih starinskih mjera valja kazati da u to vrijeme "funt"nije bila jedinstvena jedinica mase (težine) u svijetu. U upotrebi je bila „starorimska funta ( $1 \mathrm{lb}=0,327 \mathrm{~kg}$ )“, ,"trgovačka ili bečka funta ( $1 \mathrm{lb}=0,56 \mathrm{~kg}$ )“ i "ljekarnička funta $(1 \mathrm{lb}=0,42 \mathrm{~kg})$ “, a bilo je još nekoliko različitih vrijednosti funta ili funte. . 
Za pretpostaviti je da je $\mathrm{u}$ opisu vaganja i mjerenja propisanih vračtvih Lalague uzeo u obzir ljekarničku funtu. Prema tomu izlazi da je temeljna jedinica tog sustava 1 zerno (zrno ječma srednje veličine) imalo masu 45,573 mg.

\section{ZAKLJUČAK}

U ovom popisu ljekovitog bilja i ostalih tvari koje autor navodi kao vračtva ladanjska, prikazano je ukupno 157 jedinica. Od tog broja, samoniklog bilja ili trava je 101, uzgojnog bilja 31 vrsta, tvari koje možemo označiti kao organske izlučevine: loj, mlijeko, med, mirha ili plemenita mast, španjolska muha je 5, anorganskih tvari: bersa vinska, galic beli, gruda zemlje iz Armenije, jalun (alaun), kafra (kamfor), kina, blaibas farba, železo, žveplo (sumpor), salitra, sol, sol žuhka, sopun, tamjan, terpentin, živo vapno, zelenoča kufra (bakrena gleđa), dakle ukupno 17 tvari. Kao kuriozitet ove Lalangove farmakopeje je ubrajanje u vračtva i nekih ekskremenata, primjerice: lanje (izmet) golubovo, lanje konjsko, scalina človečanska (ljudska mokrača).

Broj vrsta ljekovitog bilja naveden u knjizi samo je oko jedne četvrtine broja vrsta koje se iskazuju u večini ljekaruša toga doba. U popisu nema naširoko poznatih ljekovitih biljka kao što su: bosiljak, matičnjak, mravinac, neven, trnina, vodopija, petrovac koje su i danas obvezni sastojak "bakine apoteke". Zašto taj broj nije veći i zašto su neke biljke izostavljene? Moglo bi se posumnjati da autor nije bio dovoljno upućen u ljekarničku botaniku, što treba odmah otkloniti obzirom na njegovu solidnu lječničku naobrazbu. Broj opisanih vrsta ljakovitog bilja moramo dovesti u suglasje s bolestima o kojima govori u knjižici. Spominje "vračtvene trave" kojima se liječe vručice, zimice nutarnje i vanjske, upale pluča ili bodec, upale grla, katar, gute, sunčanice, kostobolja, kozice, vrbanec, pljuvanje krvi, grčevi u crijevu, gnjila zimica, miserere, griže, bjesnoče. Za liječenje tih i običnom puku najpoznatijih bolesti navedene su i najdostupnije biljke, biljke iz neposrednog okoliša. Ostale ljekovite tvari mogu se uz pristupačne cijene nabaviti u ondašnjim ljekarnama. $U$ to vrijeme nema preciznih dijagnoza bolesti u današnjem smislu pa je i liječenje biljem temeljeno na njihovom širokom djelovanju. Uspjeh je ovisio poglavito o lječničkom i ljekarničkom iskustvu.

Pisac je stanovitom redukcijom opisa najčešćih bolesti i primijenjenih ljekova nastojao sadržaj knjižice približiti puku. Dakako, najprije onima koji su u to vrijeme znali čitati.

Pored ljekarničkog i botaničkog značaja knjižica Vračtva ladanjska zasigurno ima i jezikoslovno značenje. Tekst privlači pozornost svojim starokajkavskim hrvatskim jezikom, koji danas zbog svoje stilistike i sintakse izgleda i nama kajkavcima zakučast i teško razumljiv. Međutim, on krije dosta elemenata za usporedna 
jezikoslovna istraživanja. Lalangue je djelo izvorno napisao na latinskom jeziku. Prevoditelj franjevac Edmund Platušić nastojao je da izražajnim rečenicama u kajkavštini predstavi sadržaj. Zbog toga su poneke misli iskazane u predugačkim rečenicama. Unatoč tomu čitajući tu našu starinu, čovjeka obuzima stanovita nostalgija za lijepim nestalim kajkavskim govorom.

\section{RJEČNIK TEŽE RAZUMLJIVIH RIJEČI}

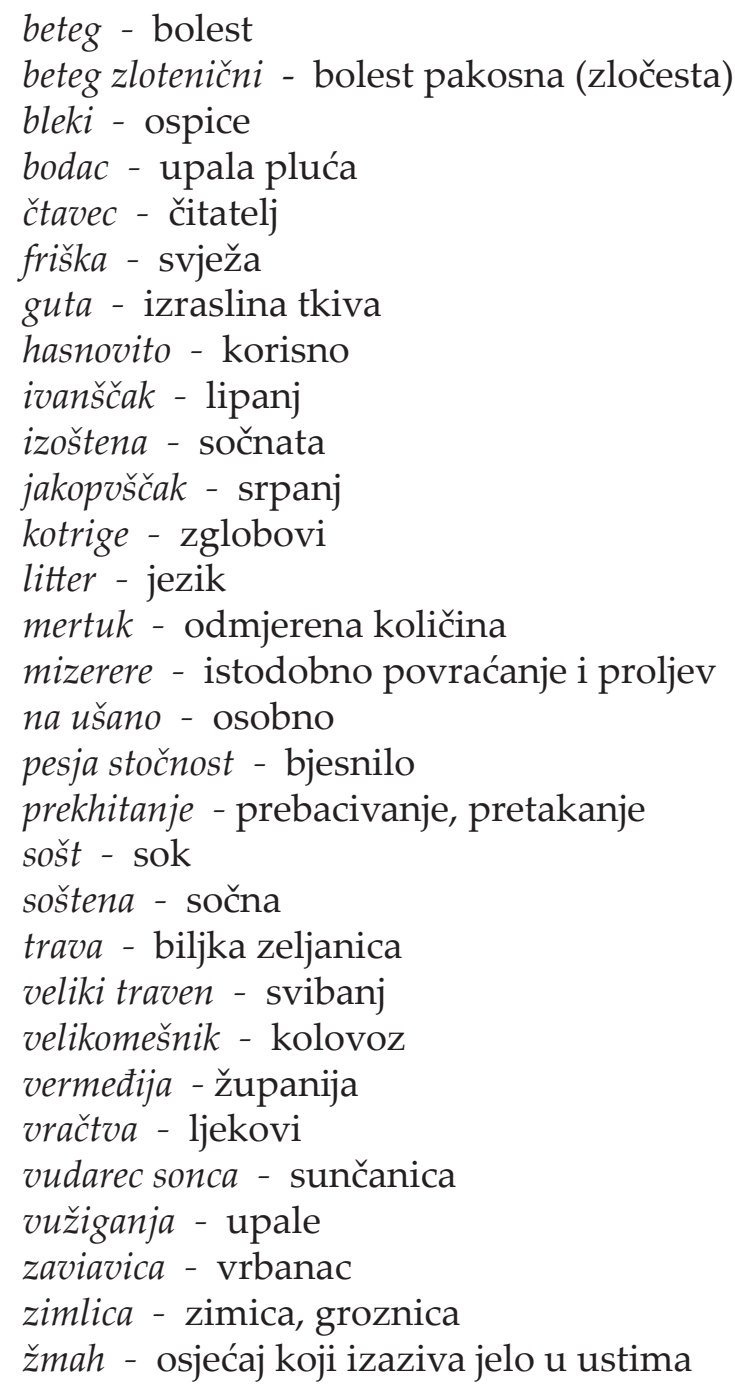




\section{NAJVAŽNIJA LITERATURA}

1. „Priroda“, 5-6 /15., dvobroj: Botanički vrtovi i arboretumi Hrvatske, HPD, Zagreb.

2. Z. BARTOLIĆ, 2009., Međimurski pjesnik, slikar, kipar i skladatelj Florijan Andrašec, nakladnik Franjo Božić, Njivice otok Krk.

3. J. FELIX, J. TOMAN, K. HISEK, 1974., Der Grose Naturführer, Kosmos, Stuttgart.

4. N. GELENČIR, 1975., Prirodno liječenje biljem, Nakladni zavod Znanje, Zagreb.

5. V. GLIGIĆ, 1954., Etimološki botanički rečnik, "Veselin Masleša“ Sarajevo.

6. D. GRDENIĆ, 2001., Povijest kemije, Novi Liber, Zagreb, Školska knjiga, Zagreb.

7. N. HULINA, 1998., Korovi, Školska knjiga, Zagreb.

8. F. KUŠAN, 1938., Ljekovito bilje, vlastita naklada, Zagreb.

9. T. LIPLJIN, 2002: Rječnik varaždinskog kajkavskog govora, Stanek, Varaždin.

10. K. MÄGDEFRAU, F. EHRENDORFER, 1978., Botanika sistematika, evolucija $i$ geobotanika, Školska knjiga, Zagreb.

11. I. PADOVAN, glavni urednik, 1992: Medicinski leksikon, Leksikografski zavod Miroslav Krleža", Zagreb.

12. T. ŠARIĆ, 1978., Atlas korova, IGKRO "Svjetlost", Sarajevo.

13. I. ŠUGAR, 2008., Hrvatski biljni imenoslov, Matica hrvatska, Zagreb.

14. N. VAJS, 2003., Hrvatska povijesna fitonimija, Institut za hrvatski jezik i jezikoslovlje, Zagreb.

15. D. VARGA, 2015: Hrana, kuhinja i blagovanje u doba Zrinskih, Izdavačka kuća Meridijani, Samobor. 


\section{SAŽETAK}

\section{LJEKOVITO BILJE I OSTALE LJEKOVITE TVARI U DJELU IVANA KRSTITELJA LALANGUA IZ 1776. GODINE}

Svijetao primjer Ivana Krstitelja Lalangua pokazuje da je Hrvatska već stoljećima sastavni dio Europe. Živahna razmjena ljudi i ideja odvija se od vremena pokrštavanja Hrvata do danas. U radu je prikazan rad jednog takvog došljaka iz zapadne Europe, koji ne samo da liječi bolesne, nego svojim spisateljskim radom nastoji podići stupanj prosvjećenosti običnoga puka. Njegova farmakopeja je i s gledišta ondašnje medicinske znanosti veoma jednostavna. U nju je uvrstio ljekovite biljke i druge ljekovite tvari koje su široko dostupne svima. Težište ovoga rada je na izvornom opisu pojedinih vračtvenih trav, prepisano radi čitlivosti na današnje pismo. Rad je dopunjen kratkim pregledom najznačajnijih dictionara (rječnika) i likaruša naših starijih autora. Opseg fitonimije u njima pokazuje u kojoj su mjeri ljudi određenog vremena bili upućeni u poznavanje biljaka i njihovu ljekovitost. Iako je Lalangue svoje prosvjetiteljske knjižice izvorno pisao na latinskom jeziku, koje su prevodili hrvatski franjevci, ipak je stekao častan naziv - začetnik hrvatske medicinske književnosti.

Ključne riječi: liječnik; vračtva; trave; dikcionar; dijački; nemški; ivanščak; zerno; funt; pint, ljekaruša, starokajkavština. 


\section{SUMMARY}

\section{MEDICINAL PLANTS AND OTHER MEDICINAL SUBSTANCES IN THE WORK OF JOHN THE BAPTIST LALANGUE FROM THE YEAR OF 1776}

The bright example of John the Baptist Lalangue proves that Croatia has been an integral part of Europe for centuries. A dynamic exchange of people and ideas has taken place ever since Croats were baptised. The paper deals with one such foreigner from Western Europe who not only healed sick people, but through his writings also strived to increase the level of enlightenment among common people. His pharmacopeia is very simple even from the perspective of the then medical science. It comprises medicinal plants and other medicinal substances that are easily available to everyone. This paper highlights the original description of certain medicinal herbs and is written in today's language in order to facilitate the reading. The paper also contains an appendix listing the most important dictionaries and recipes by our older authors. The proportion of included pharmacopeia indicates the extent to which people living in a certain period of time were familiar with plants and their healing properties. Even though Lalangue wrote his enlightenment booklets, translated by Croatian Franciscans, originally in Latin, he nevertheless gained the honourable title of the father of Croatian medical literature.

Key Words: physician; medicines, herbs; dictionary; Latin, German, June; kernel; pound, pint, herbal manuals; Old Kajkavian Dialect. ${ }^{4}$

Sažetak prevela Sanja Županić, prof. 